XI Congresso Brasileiro de Engenharia
Química em Iniciação Científica
Unicamp - Campinas - SP
19 a 22 de julho de 2015

\title{
ESTUDO DA TERMODINÂMICA DA ADSORÇÃO DOS ENANTIÔMEROS DO FÁRMACO SECNIDAZOL
}

\author{
B. S. SOUSA ${ }^{1}$, W. M. FERRARI ${ }^{1}$, A. C. NASCIMENTO ${ }^{1}$, M. A. CREMASCO ${ }^{1}$ \\ ${ }^{1}$ Universidade Estadual de Campinas, Faculdade de Engenharia Química
}

\begin{abstract}
RESUMO - O secnidazol (1-(hidroxipropil)-2-metil-5-nitroimidazol) é um fármaco que possui espectro de atividade contra microorganismos anaeróbicos e pode ser utilizado no tratamento de doenças como amebíase, giardíase e tricomoníase. Por ser rapidamente e completamente absorvido pelo organismo e por possuir tempo de meia vida maior, acarreta menos efeitos colaterais, podendo ser utilizado em doses mais baixas que do que outros 5-nitroimidazois para os mesmos propósitos. O secnidazol é comercializado na forma racêmica, no entanto estudos apontam que apenas o isômero $\mathrm{R}$ apresenta maior atividade biológica em relação ao isômero S. Dessa forma, é necessária uma separação dos isômeros de modo a obter o fármaco de interesse. Tal separação pode ser realizada por meio da técnica de cromatografia líquida de alta eficiência. Para tanto, torna-se fundamental o conhecimento de parâmetros termodinâmicos que viabilizem tal separação, como o fator de retenção, $\mathrm{k}$, e informações sobre as diferenças de entalpia e de entropia $(\Delta \mathrm{H}, \Delta \mathrm{S})$ para cada um dos enantiômeros. A obtenção de tais parâmetros é o objetivo do presente artigo, o qual apresenta valores para k, para a faixa de temperatura entre $20{ }^{\circ} \mathrm{C}$ e $35^{\circ} \mathrm{C}$. A partir de tais valores, foi possível estimar os valores de $\Delta \mathrm{H}$ e $\Delta \mathrm{S}$ tanto para o (-)-(S)-secnidazol quanto para o (+)-(R)-secnidazol, utilizando-se tris (3,5-dimetilfenilcarbamato) de amilose como fase estacionária quiral e fase móvel contendo $40 \%$ de acetonitrila e $60 \%$ de isopropanol.
\end{abstract}

\section{INTRODUÇÃO}

O secnidazol corresponde à formulação 1-(hidroxipropil)-2-metil-5-nitroimidazol, com fórmula molecular $\mathrm{C}_{7} \mathrm{H}_{11} \mathrm{~N}_{3} \mathrm{O}_{3}$ e massa molar de $185,18 \mathrm{~g} / \mathrm{mol}$ e é um dos derivados nitroimidazólicos e possui espectro de atividade contra microorganismos anaeróbicos e eficácia no tratamento de amebíase, giardíase, tricomoníase e vaginose bacteriana. $\mathrm{O}$ secnidazol é comercializado na forma racêmica, todavia estudos mostram que o fármaco é quiral, ou seja, é constituído por (-)-(S)-secnidazol e (+)-(R)-secnidazol (NASCIMENTO, 2012). Dentro deste contexto, existe uma série de vantagens relativas à administração de enantiômeros puros sobre à de mistura racêmica, podendo-se citar: redução da dose e da carga no metabolismo; ampliação do uso do fármaco; redução da variabilidade da resposta dos pacientes; aumento da atividade e redução na dosagem; aumento de especificidade e redução de efeitos colaterais. Sob este aspecto, torna-se fundamental a obtenção de enantiômeros a partir da mistura racêmica na qual estão presentes. 
Uma das propriedades presentes nos enantiômeros é o fato de algumas forças intermoleculares, que agem sobre moléculas enantioméricas, serem idênticas. Deste modo, não é possível separar enantiômeros por métodos tradicionais, feito a destilação fracionada, cristalização fracionada ou cromatografia clássica (SOLOMONS, 1996). Todavia, os métodos de separação quiral utilizando-se técnicas de cromatografia líquida (de fase estacionária) mostram-se eficientes na separação enantiomérica. Sob este aspecto, a cromatografia é um processo de separação em que a mistura da amostra é distribuída entre duas fases no leito cromatográfico, particularmente na forma de coluna. Uma fase mantém-se estacionária enquanto a outra, a líquida na presente situação, atravessa o leito cromatográfico. A separação, propriamente dita, além das características da coluna, é governada pelo fenômeno da adsorção. Torna-se, portanto, fundamental, para o estudo da adsorção e por via de consequência da própria separação quiral, a compreensão da termodinâmica da adsorção. Sob este aspecto, a análise termodinâmica pode iniciar-se a partir do método cromatográfico, no intuito de expressar a energia de Gibbs em termos do fator de retenção, $k$, e da razão de fase na coluna $\phi$ (volume da fase estacionária pelo volume da fase móvel) na forma (NASCIMENTO, 2012)

$$
\Delta \mathrm{G}=-\mathrm{RT} \ell \mathrm{n}\left(\frac{\mathrm{k}}{\phi}\right)
$$

com

$$
\phi=\frac{1-\varepsilon_{\mathrm{T}}}{\varepsilon_{\mathrm{T}}}
$$

em que $\varepsilon_{T}$ é a porosidade total da coluna cromatográfica, possível de ser obtida por meio da técnica do pulso cromatográfico (CREMASCO et al., 2001),

$$
\frac{\mathrm{L}}{\mathrm{t}_{\mathrm{R}}}=\frac{\mathrm{u}_{0}}{\varepsilon_{\mathrm{T}}}
$$

na qual $\mathrm{L}$ é o comprimento característico da coluna cromatográfica; $\mathrm{u}_{0}$, velocidade superficial da fase móvel, $\mathrm{u}_{0}=4 \mathrm{Q} / \pi \mathrm{D}^{2}$, sendo $\mathrm{Q}$ a vazão volumétrica do líquido e $\mathrm{D}$, o diâmetro da coluna cromatográfica; $t_{R}$ é o tempo de retenção, obtido de $t_{R}=t_{\exp }-t_{0}$, sendo $t_{\exp }$ o tempo de retenção total na coluna, $\mathrm{t}_{0} \mathrm{o}$ tempo associado ao volume morto da coluna. $\mathrm{A}$ obtenção de $\varepsilon_{\mathrm{T}}$ resulta da inclinação da reta $\mathrm{L} / \mathrm{t}_{\mathrm{R}}$ vs. $\mathrm{u}_{0}$, para distintas vazões.

Para a obter as variações de entalpia, $\Delta H$, e de entropia, $\Delta S$, recorre-se à relação de Gibbs-Helmholtz, ,

$$
\Delta \mathrm{G}=\Delta \mathrm{H}-\mathrm{T} \Delta \mathrm{S}
$$

Deste modo, retoma-se a Equação 1, considerando-se a Equação 4, segundo

$$
\ln \left(\frac{\mathrm{k}}{\phi}\right)=-\frac{\Delta \mathrm{H}}{\mathrm{RT}}+\frac{\Delta \mathrm{S}}{\mathrm{R}}
$$


sendo

$$
\mathrm{k}=\frac{\mathrm{t}_{\mathrm{R}}-\mathrm{t}_{\mathrm{M}}}{\mathrm{t}_{\mathrm{M}}}
$$

em que $t_{M}$ é o tempo de retenção de um componente não retido pela fase estacionária. Na Equação 5, $T$ refere-se à temperatura absoluta e $R$, à constante universal dos gases.

Ressalte-se que $\Delta H$ e $\Delta S$ representam a diferença de entalpia e de entropia na situação em que certo enântiomero ( $\mathrm{R}$ ou $\mathrm{S}$ ) é transferido da fase móvel para a fase estacionária. Quando a superfície cromatográfica e as propriedades do eluente e do analito não variam significativamente com a temperatura, $\Delta H$ e $\Delta S$ também são invariantes com a temperatura e o gráfico de $\ln (k / \phi)$ vs. $1 / T$, reconhecido como gráfico de van't Hoff, será linear (FORNSTEDT et al., 1997). Desse modo, do ajuste da Equação 5, para o gráfíco experimental de van't Hoff, pode-se obter $\Delta H$ por meio do coeficiente angular da reta, e o valor de $\Delta S$ da intersecção de tal reta com o eixo da ordenada.

\section{MATERIAIS E MÉTODOS}

O secnidazol racêmico foi cedido pela empresa EMS® (S. Bernardo dos Campos, SP). Para a fase estacionária quiral, utilizou-se coluna cromatográfica de aço inoxidável, recheadas com a fase estacionária quiral tris (3,5-dimetilfenilcarbamato) de amilose, do tipo coluna analítica Chiralpak ${ }^{\circledR}$ AD $(150$ x $3,9 \mathrm{~mm}, 10 \mu \mathrm{m})$, adquirida da empresa Chiral Technologies ${ }^{\circledR}$.

Os experimentos foram realizados em um sistema de cromatografia líquida de alta eficiência (CLAE), constituído por uma bomba Modelo LC-20AT, por um detector UV-VIS Modelo SPD-20A e por uma controladora Modelo CBM-20A/UFCL, todos da marca Shimadzu Corporation ${ }^{\circledR}$. No sistema estão presentes uma válvula injetora do tipo Rheodyne Modelo 7725i (EUA) e um detector baseado em dicroísmo circular Modelo CD-2095 Plus da Jasco ${ }^{\circledR}$ (Japão). As amostras foram injetadas manualmente com o auxílio de uma seringa de $250 \mu \mathrm{L}$ Modelo Microliter ${ }^{\mathrm{TM}} 725$ (Hamilton Co., EUA).

Para a obtenção do valor da porosidade total utilizou-se uma solução de TTBB em isopropanol com concentração 0,5 g.L $\mathrm{L}^{-1}$ e vazões 0,$6 ; 0,8 ; 1,0 ; 1,2 \mathrm{~mL} \cdot \mathrm{min}^{-1}$ à $25^{\circ} \mathrm{C}$. A amostra foi injetada com uma seringa de $250 \mu \mathrm{L}$ no CLAE e para cada vazão registrou-se o tempo de retenção. No caso dos parâmetros termodinâmicos foram injetadas amostras de solução contendo secnidazol com concentração 0,5 g.L $\mathrm{L}^{-1}$ diluído em fase móvel contendo $40 \%$ de acetonitrila e $60 \%$ de isopropanol à $20^{\circ} \mathrm{C}, 25^{\circ} \mathrm{C}, 30^{\circ} \mathrm{C}$ e $35^{\circ} \mathrm{C}$ à vazão de $1 \mathrm{ml} . \mathrm{L}^{-1}$. Ressalte-se que o volume morto encontrado foi $\mathrm{V}_{\mathrm{D}}=0,10 \mathrm{~cm}^{3}$ e o $\mathrm{t}_{\mathrm{M}}=1,0 \mathrm{~min}$. Todos os ensaios foram feitos em duplicata.

\section{RESULTADOS}

O valor da porosidade total adveio da Equação 3. Para tanto foram realizados ensaios, cujo gráfico $L / t_{R}$ vs. $u_{0}$, forneceu uma reta de coeficiente de determinação, $R^{2}$, igual a 0,999 . A partir do coeficiente angular, encontrou-se o valor de 0,57 para a porosidade total, a partir 
do qual e de posse da Equação 2, chegou-se no valor $\phi=0,754$. Para os fatores de retenção do enantiômero i ( $\mathrm{i}=\mathrm{R}$ ou $\mathrm{S}$ ), foram utilizados os cromatogramas, obtendo-se os tempos de retenção e, destes, os valores de $k$. A Figura 1 apresenta os resultados para tais grandezas.

Figura 1 - Fatores de retenção, k, para os enantiômeros do secnidazol.

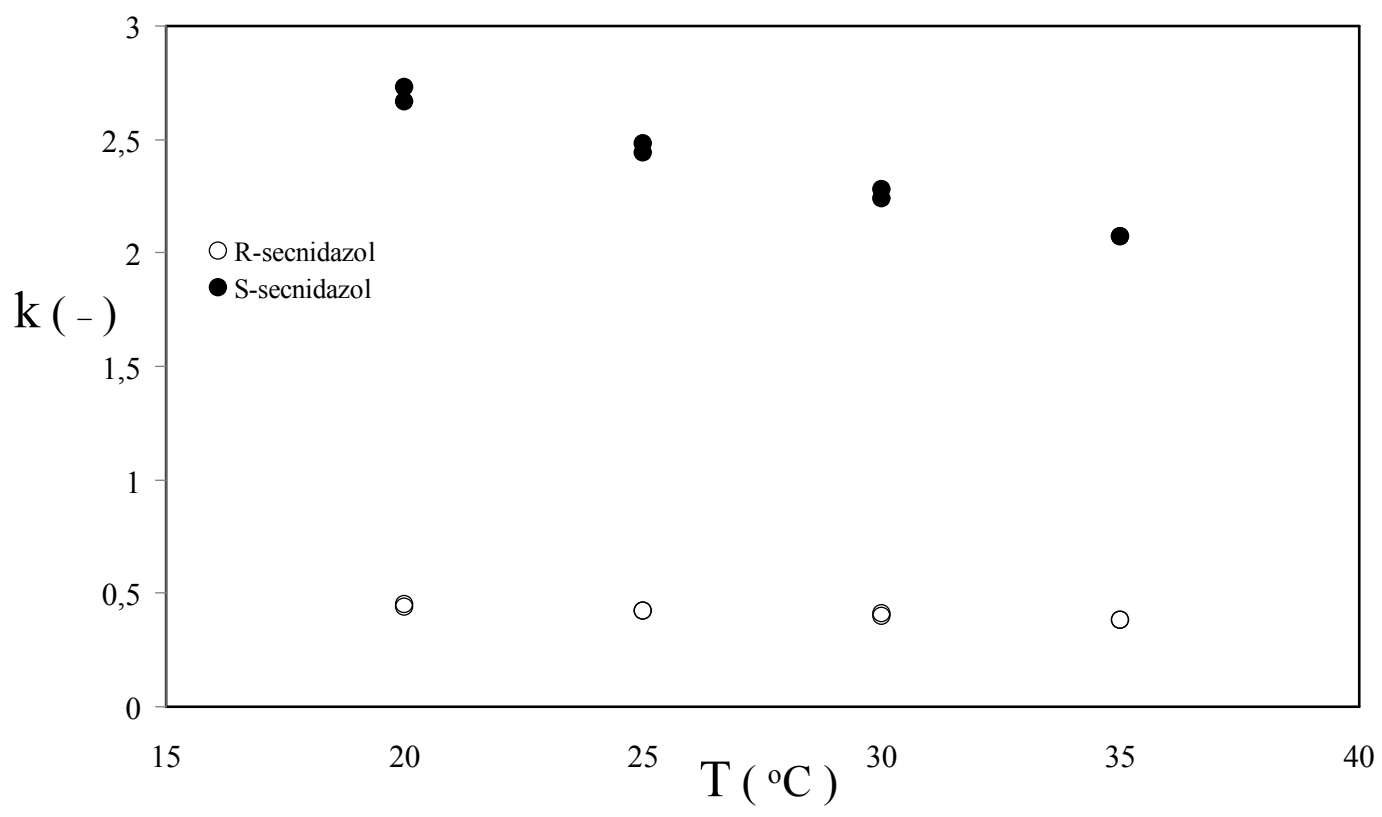

De posse dos valores apresentados na Figura 1, construiu-se o gráfico $\ln (k / \phi) v s .1 / T$,

Observa-se, nesta, retas que, utilizando-se a Equação 5, foram obtidos os resultados para $\Delta H$ e $\Delta S$, considerando-se $R=8,3144 \mathrm{~J}_{\mathrm{mol}} \mathrm{mol}^{-1} \mathrm{~K}^{-1}$, conforme apresentados na Tabela 1 , na qual estão os valores dos coeficientes de determinação relativos às retas.

Tabela 1 - Grandezas termodinâmicas dos enantiômeros do secnidazol.

\begin{tabular}{cccc}
\hline & $\Delta \mathrm{S}$ & $\Delta \mathrm{H}\left(\mathrm{kJ} \cdot \mathrm{mol}^{-1}\right)$ & $\mathrm{R}^{2}$ \\
\hline $\begin{array}{c}(+)-(\mathrm{R})- \\
\text { secnidazol }\end{array}$ & $-28,98$ & $-7,20$ & 0,993 \\
$\begin{array}{c}(-)-(\mathrm{S})- \\
\text { secnidazol }\end{array}$ & $-34,38$ & $-13,18$ & 0,981 \\
\end{tabular}


Figura 2 - Obtenção de parâmetros termodinâmicos para os enantiômeros do secnidazol.

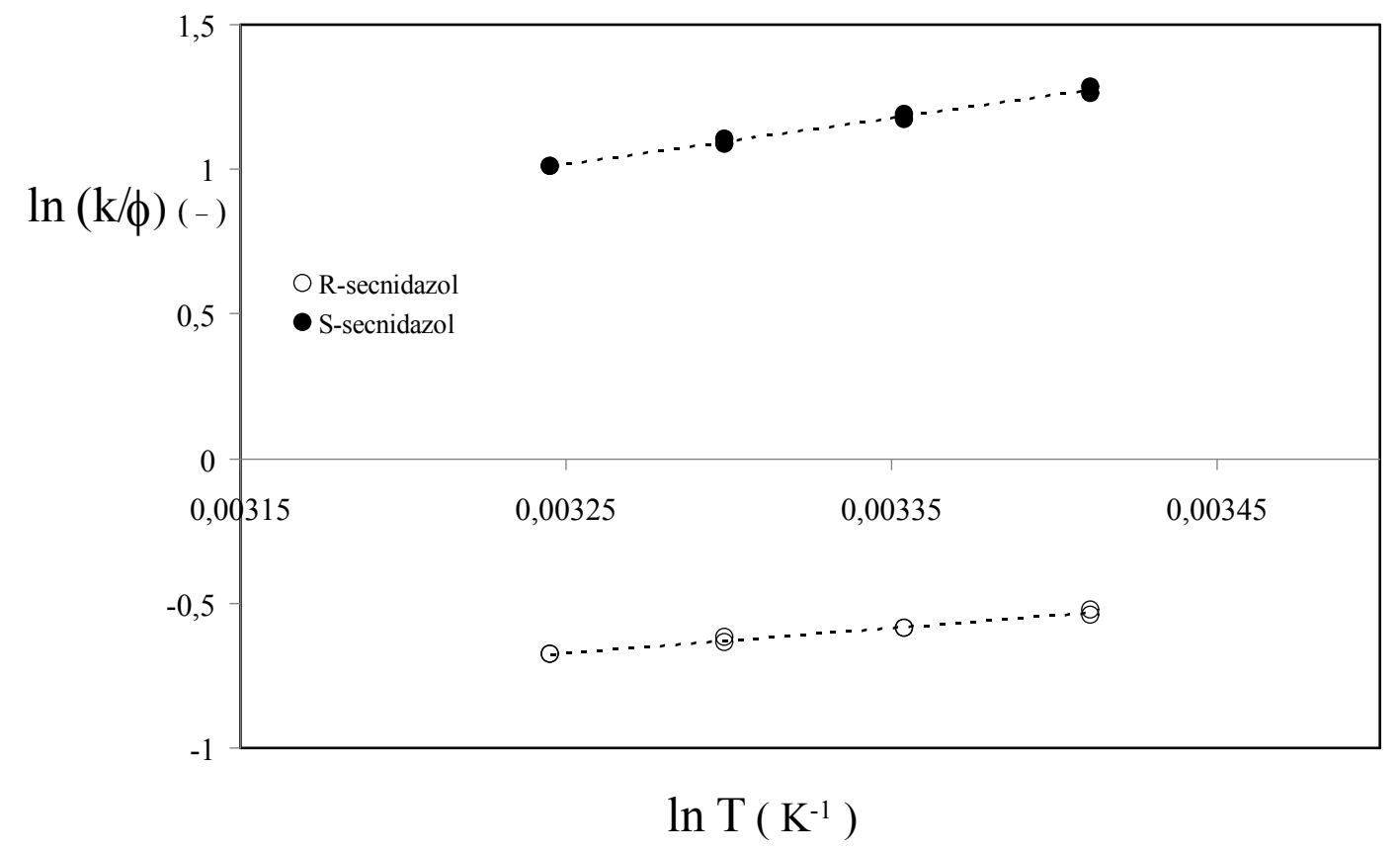

\section{CONCLUSÃO}

Tendo como objetivo o estudo da termodinâmica da adsorção do fármarco quiral secnidazol, foram obtidas grandezas essenciais para a compreensão do fenômeno adsortivo, como também para futuras aplicações de separação enantiomérica. $\mathrm{O}$ modelo proposto, tendo como fundamento a equação clássica de van’t Hoff, mostrou-se bastante adequado com valores de coeficientes de determinação superiores a 0,98 para as diferenças de entalpia e de entropia. Ressalte-se que os valores negativos para as grandezas termodinâmicos comprovam que é favorável energeticamente aos solutos adsorverem-se à fase estacionária e, isto ocorre com o predomínio da entropia.

\section{REFERÊNCIAS BIBLIOGRÁFICAS}

CREMASCO, M. A.; WANG, N.-H. L.; HRITZKO, B. J. Parameters estimation for amino acids adsorption in a fixed bed by moment analysis. Braz. J. Chem. Eng., v. 18, n. 1, p. $181,2001$.

FORNSTEDT, T.; SAJONS, P.; GUIOCHON, G. Thermodynamic study of an unusual chiral separation. Propranolol enantiomers on an immobilized cellulase, J. Am. Chem. Soc., v. 119, p. 1254, 1997. 
NASCIMENTO, A. C. Resolução enantiomérica do secnidazol. Campinas: Faculdade de Engenharia Química, Universidade Estadual de Campinas, 2012. 122 p. Dissertação (Mestrado).

SOLOMONS, T. W. G. Química orgânica, v.1. Rio de Janeiro: Livros Técnicos e Científicos, 1996, 777 p. 